Article

\title{
Evaluating the Impacts of Pumping on Aquifer Depletion in Arid Regions Using MODFLOW, ANFIS and ANN
}

\author{
Mohammed R. Almuhaylan ${ }^{1}$, Abdul Razzaq Ghumman ${ }^{2}{ }^{2}$, Ibrahim Saleh Al-Salamah ${ }^{2}$, \\ Afaq Ahmad ${ }^{3}\left(\mathbb{D}\right.$, Yousry M. Ghazaw ${ }^{2,4}$, Husnain Haider ${ }^{2, *}{ }^{-}$and Md. Shafiquzzaman ${ }^{2}$ \\ 1 Graduate Student, Department of Civil Engineering, College of Engineering, Qassim University, Buraydah, \\ Qassim 51452, Saudi Arabia; mohammed.9902@gmail.com \\ 2 Department of Civil Engineering, College of Engineering, Qassim University, Buraydah, \\ Qassim 51452, Saudi Arabia; abdul.razzaq@qec.edu.sa (A.R.G.); alsalamah@qec.edu.sa (I.S.A.-S.); \\ ghazaw@qec.edu.sa (Y.M.G.); shafiq@qec.edu.sa (M.S.) \\ 3 Department of Civil Engineering, University of Engineering \& Technology, Taxila 47080, Pakistan; \\ afaq.ahmad@uettaxila.edu.pk \\ 4 Department of Irrigation and Hydraulics, College of Engineering, Alexandria University, \\ Alexandria 21544, Egypt \\ * Correspondence: husnain@qec.edu.sa
}

Received: 10 July 2020; Accepted: 13 August 2020; Published: 15 August 2020

check for updates

\begin{abstract}
In arid regions, the groundwater drawdown consistently increases, and even for a constant pumping rate, long-term predictions remain a challenge. The present research applies the modular three-dimensional finite-difference groundwater flow (MODFLOW) model to a unique aquifer facing challenges of undefined boundary conditions. Artificial neural networks (ANN) and adaptive neuro fuzzy inference systems (ANFIS) have also been investigated for predicting groundwater levels in the aquifer. A framework is developed for evaluating the impact of various scenarios of groundwater pumping on aquifer depletion. A new code in MATLAB was written for predictions of aquifer depletion using ANN/ANFIS. The geotechnical, meteorological, and hydrological data, including discharge and groundwater levels from 1980 to 2018 for wells in Qassim, were collected from the ministry concerned. The Nash-Sutcliffe efficiency and mean square error examined the performance of the models. The study found that the existing pumping rates can result in an alarming drawdown of $105 \mathrm{~m}$ in the next 50 years. Appropriate water conservation strategies for maintaining the existing pumping rate can reduce the impact on aquifer depletion by $33 \%$.
\end{abstract}

Keywords: groundwater; MODFLOW; ANN; groundwater modeling; arid regions; groundwater aquifer

\section{Introduction}

Groundwater modeling for sustainable management is an important field in regions that use groundwater as their main water supply. The matter becomes more serious where the recharge to the aquifer is limited and the groundwater is depleting at an alarming rate (Figure 1). So, it is a hot issue and relevant research has been addressing various issues of groundwater worldwide [1-3]. However, there are several challenges in groundwater modeling used to provide some of the basic information for engineering designs, sustainable groundwater planning, and environmental impact assessment. Challenges exist in understanding system dynamics and the flow patterns, analyzing the groundwater responses to stresses in the system, and assessing the sustainable groundwater yield. In short, groundwater modeling is an area of continued research, as identified by several publications [4-9]. The groundwater flow is governed by the well-known Boussinesq equation. A variety of computer 
programs have been developed to solve this equation. Mainly, finite element or finite difference techniques are used for this purpose. MODFLOW, PLASM, and AQUIFEM-1 to AQUIFEM-N are a few examples of such software [8,10]. MODFLOW provides the most commonly used solution of the equation based on finite differences. This model has been used by several researchers from the early 1980s to 2020 [4,11-15]. In spite of the long-term use of numerical modeling for groundwater, there remains space for further research in this field of specialization because of the unique problems with various aquifers $[16,17]$.

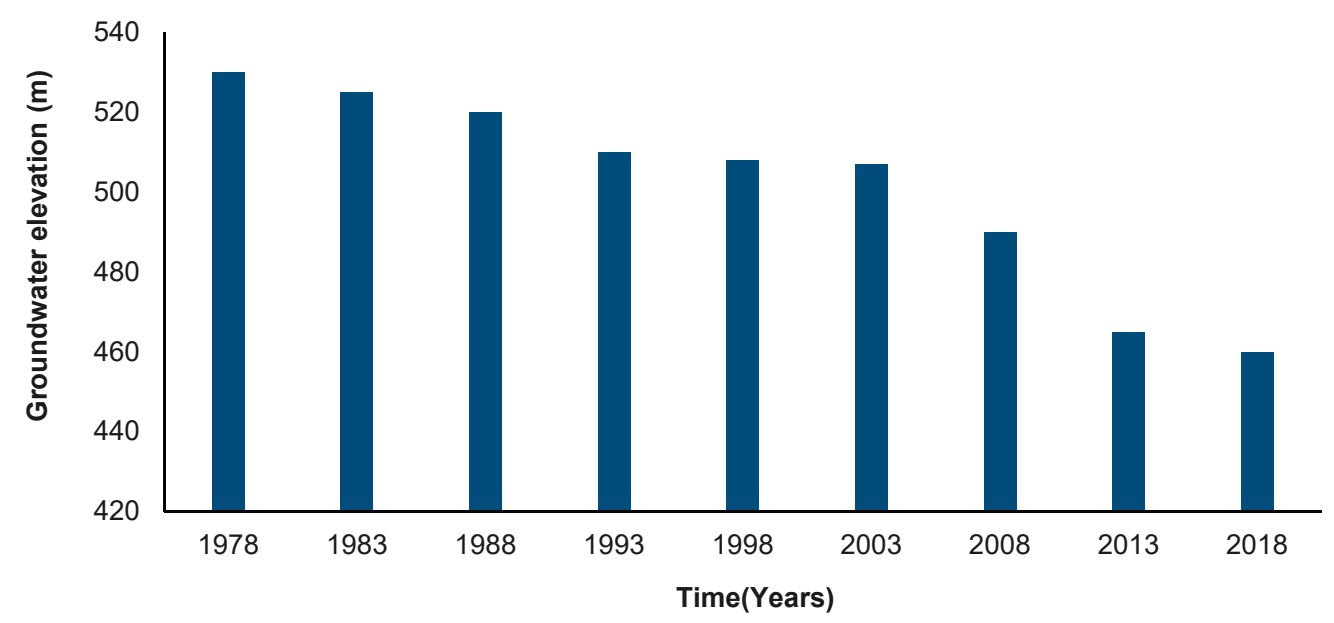

Figure 1. Depletion of groundwater levels of Saq Aquifer in Qassim Region.

The modeling of aquifers becomes highly challenging if the boundary conditions are not well defined for their certain parts. Pujades et al. [18,19] comprehensively identified the difficulties associated with solving the problems of groundwater flow modeling with unknown boundary conditions and aquifer parameters. They have sought solutions to these problems by using approximate and numerical methods applicable to a specific groundwater flow situation characterized by its hydraulic behavior of diaphragm walls of cut and cover tunneling and an underground enclosure. They used pumping tests data to obtain the aquifer parameters (hydraulic conductance and specific storage) by the Theis method [20]. Pujades et al. [21] used pumping tests data to obtain the same aquifer parameters by Cooper and Jacob's method [22]. Although the previous studies have provided guidelines to solve the problem of unknown boundary conditions and for the estimation of aquifer parameters, their pragmatism can only be evaluated by applying them to diverse cases with site-specific constraints [23-26].

A part of the Saq Aquifer in Qassim, Saudi Arabia also has no well-defined boundary conditions. In the first objective of the present study, we addressed the problem of the boundary conditions and other aquifer parameters using hit and trial and the calibration subroutine of MODFLOW. There is also a need to address the above-mentioned problem through alternative, relatively simpler, modeling techniques. Several artificial intelligences based techniques have been found as useful alternatives, e.g., artificial neural networks (ANN), adaptive neuro fuzzy inference systems (ANFIS), particle swarm optimization-neuro fuzzy inference systems (PSO-ANFIS), support vector regression (SVR), bidirectional long short-term memory (Bi-LSTM) network, and gated recurrent unit (GRU). Elbaz et al. [27,28] integrated PSO-ANFIS with genetic algorithm models to predict the earth pressure balance for the performance of a shield via tunneling at a site in China. The very small error found between the observed and simulated earth pressure balance showed the high performance of their models. Recently, Gao et al. [29] used GRU for solving a similar problem in Luoyang, China. Although the application of these deep learning arterial intelligence models in the field of groundwater predictions is relatively rare to date, some researchers used the ANN, ANFIS, and SVR to simulate groundwater-levels [30-36]. 
Panahi et al. [37] used convolutional neural network and SVR models to map groundwater but did not address the challenges associated with the in-depth-analysis of groundwater levels. Fan et al. [38] applied machine learning methods to analyze pumping tests to determine the aquifer parameters. They concluded that the machine learning models can successfully help to analyze the pumping tests for the estimation of aquifer parameters. Chen et al. [39] compared the application of machine learning in groundwater modeling with numerical techniques. They found that the performance of machine learning models (ANN and SVR) is better than that of hydraulic models for short-term predictions. However, hydraulic techniques of groundwater simulations are based on physical laws and these are much better methods than the artificial intelligence models in general (Table 1). Nevertheless, extensive aquifer data is required for use of these models. Their study showed that further research is required to further explore the use of ANN in the field of groundwater modeling. Accordingly, the second objective of the present paper is to find a simple solution to the problem of undefined boundary conditions of aquifers using ANN and ANFIS models.

Table 1. Comparison of GCM with data-driven models ANN and ANFIS.

\begin{tabular}{|c|c|c|c|}
\hline Characteristics & Hydraulic Model & ANN/ANFIS & Remarks \\
\hline $\begin{array}{l}\text { Computational } \\
\text { expenses (need high } \\
\text { speed computers and } \\
\text { time for computations) }\end{array}$ & High & Moderate & $\begin{array}{l}\text { - } \quad \text { Comparatively higher computing facilities are } \\
\text { required for hydraulic models. } \\
\text { Moderate computing power may function } \\
\text { adequately for the ANN. }[8,39]\end{array}$ \\
\hline $\begin{array}{l}\text { Data and model } \\
\text { processing requirements }\end{array}$ & Complex & $\begin{array}{l}\text { Moderately } \\
\text { complex }\end{array}$ & $\begin{array}{l}\text { - } \\
\text { Requires precise values of aquifer parameters } \\
\text { and high resolution mesh with lower } \\
\text { computational time steps. } \\
\text { Data of a specific aquifer are used to predict the } \\
\text { future water levels and quality parameters in } \\
\text { ANN/ANFIS application. }[8,10,32,33,39]\end{array}$ \\
\hline Model Type & $\begin{array}{l}\text { Physically } \\
\text { distributed }\end{array}$ & $\begin{array}{c}\text { Black-box (data } \\
\text { driven) }\end{array}$ & $\begin{array}{l}\text { - } \quad \text { Hydraulic models incorporate physical processes } \\
\text { and laws involved in predicting groundwater } \\
\text { levels and quality parameters. } \\
\text { ANN/ANFIS are data-driven models and do not } \\
\text { - } \\
\text { involve any physical processes. These models } \\
\text { only use the data observed during training, } \\
\text { testing, and predictions. }[10,32,33,39]\end{array}$ \\
\hline Model bias & Moderate to good & $\begin{array}{l}\text { Good for } \\
\text { specific data } \\
\text { but limited in } \\
\text { generality }\end{array}$ & $\begin{array}{l}\text { - The biases are of varying magnitude (wide range } \\
\text { of variation) in hydraulic model projections. } \\
\text { - The biases are limited to a certain range in most } \\
\text { cases of data-driven model projections, but } \\
\text { ANNs/ANFIS lack generality. }[8,10,32,33,39]\end{array}$ \\
\hline $\begin{array}{l}\text { Long-term future } \\
\text { predictions }\end{array}$ & $\begin{array}{l}\text { Easy, once the } \\
\text { model is } \\
\text { calibrated }\end{array}$ & Challenging & $\begin{array}{l}\text { - } \quad \text { Long-term future predictions are easy once the } \\
\text { hydraulic model is calibrated and validated. } \\
\text { - } \quad \text { High expertise and experience of specific } \\
\text { problem is required for long-term future } \\
\text { predictions by ANN/ANFIS. Expertise is } \\
\text { required for the normalization and } \\
\text { de-normalization of data. }[8,10,32,33,39]\end{array}$ \\
\hline
\end{tabular}

The third objective of this study is the use of ANN/ANFIS models for long-term future predictions of groundwater levels to explore the aquifer depletion. Most of the Gulf countries are water-stressed and require sustainable groundwater planning and management [40]. The Saq Aquifer in the Qassim Region of Saudi Arabia represents a unique characteristic of arid regions, i.e., the aquifer recharge is almost negligible, but the groundwater pumping is continuous to meet municipal and irrigation requirements. The entire aquifer can ultimately dry sometime in the future if the present pumping trends continue without appropriate remedial measures. A simple but reliable groundwater model is required for this purpose. Hence, three ANN and an ANFIS models were investigated in this study and the best one was used for long-term predictions of groundwater-levels. It is worth mentioning here that most of the modelling based on ANN/ANFIS in past research dealt with only the short-term predictions of groundwater-levels [34-37,41,42]. Khedri et al. [42]. applied five various data-driven techniques for the simulation of groundwater levels. Their study only dealt with the short-term predictions of groundwater levels. According to them, models based on artificial intelligence could 
predict groundwater levels properly for one to two future months, but in the case of forecasting for three future months, the performance of these techniques was substandard. Long-term predictions using ANN/ANFIS is a challenging and novel research area, which is addressed properly in this paper. A state-of-the-art model was developed by writing a code in MATLAB for the long-term simulation of groundwater-levels using ANN/ANFIS.

Although there is no conceptual difference between our model and the classical ANN model, in the classical neural network toolbox, the user cannot, (i) define initial weights of the links and bias values, (ii) define different types of activation functions between the layers, (iii) outline different training algorithms (the 12 algorithms), and (iv), most importantly, users don't have the option to select the type of the division of the database for the cross validation into subsets. Our new code facilitates defining the initial weights of the links and bias values, changing the number of hidden layers, neurons in each hidden layer, activation functions, training algorithms, and division of data base (i.e., randomly, index, group) for the cross validation into subsets (training, validation and testing). The new ANN code is developed in a MATLAB environment due to the limitations of neural network toolbox. As author used different combinations of the above-mentioned parameters, the results of the present study show an optimized architecture of the ANN model.

It is worth mentioning here that long-term predictions for time series problems no doubt require deep learning models, such as recurrent neural networks (RNN), LSTM, convolutional neural networks $(\mathrm{CNN})$, etc. For long-term predictions, we adopted a simple approach by changing the targets and predictions into groundwater-level-changes, instead of groundwater-levels, and make it a conventional ANN/ANFIS simulation problem. Hence, we have tackled the problem of long-term simulations by training the ANN/ANFIS model for the prediction of changes in groundwater levels instead of the direct simulation of water levels. The normalization and de-normalization were made for target and predicted groundwater level changes, respectively. This makes the problem of long-term predictions similar to that dealt with the classical ANN/ANFIS models for short-term predictions. The impacts of various pumping rates on groundwater levels are studied to find an optimal solution for reducing the depletion of Saq aquifer.

The results of ANFIS are added in this research to check the efficiency of a hybrid type artificial intelligence model. ANFIS integrates the neural networks with the fuzzy rule-based system to accommodate the system uncertainties. First, this integrated approach develops a fuzzy model that derives its input variables from the fuzzy rules defined based on the input-output data. Next, the neural network tweaks these rules and generates the final ANFIS model.

\section{Materials and Methods}

\subsection{Methodological Framework}

In the present study, we used two types of techniques, including the hydraulic model MODFLOW and the data-driven models (ANN and ANFIS), to explore the Saq Aquifer depletion. A brief comparison of these models is given in Table 1. A framework illustrating the overall methodology is shown in Figure 2. The method used in this study comprised three main steps. The first step consisted of data collection regarding groundwater-levels, pumping rates, well locations, and aquifer parameters of the study area. We normalized the data regarding pumping rates and groundwater-levels for ANN and ANFIS models. The second step was to calibrate/train/test/validate the hydraulic and ANN/ANFIS models. Part of the data (say 23 years out of 38 years, i.e., $60 \%$ ) was used for training/calibration and the remainder was used for testing/validation. So, the data were divided into three parts, namely $60 \%$, $20 \%$, and $20 \%$, respectively, for the training, testing, and validation of ANN/ANFIS models and two parts, $60 \%$ and $40 \%$, for the calibration and validation of the hydraulic model. Coding was prepared in MATLAB to develop an ANN and ANFIS to accomplish the required objectives. In the third step, the models were applied for future predictions of groundwater levels to study the aquifer depletion. The rate of groundwater use is increasing day after day because of the population increase and the 
ever-rising standards of living. According to a report from the Ministry of Water and Electricity Saudi Arabia, the population growth rate is about 3\% in the Riyadh and Qassim Regions [43]. A total of four future scenarios for various pumping rates were examined to explore the aquifer depletion. Three scenarios were built with an increase in the prevailing water extraction rate by $1 \%, 2 \%$ and $3 \%$ per year from 2020 to 2070 . The fourth scenario was examined by continuing a constant rate of pumping from 2018 to 2070 without any change in the pumping rate as observed in 2018.

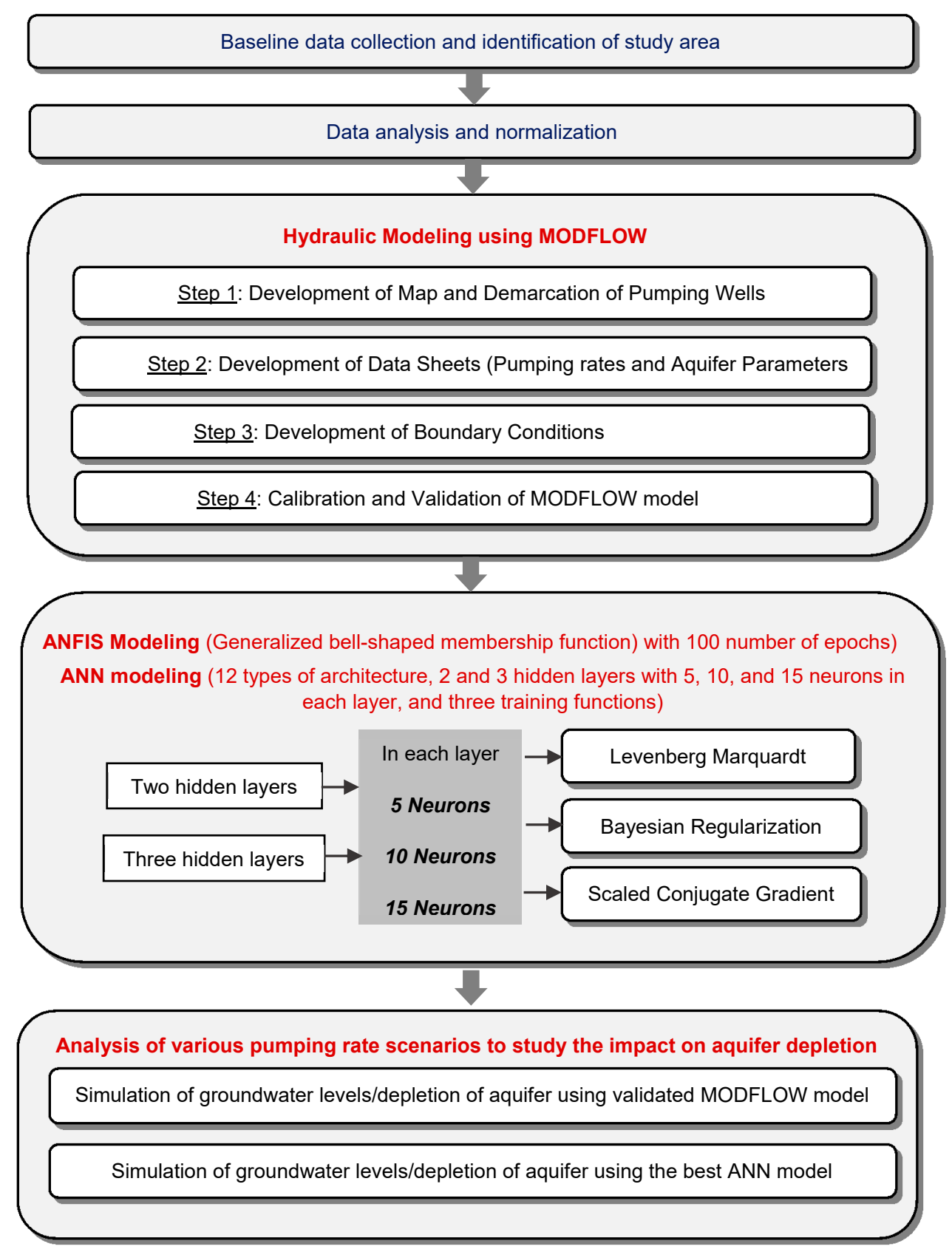

Figure 2. Groundwater Modeling Framework to Explore the Impacts of Pumping on Depletion of Aquifer.

\subsection{Study Area}

Our study area included one of the most important cities of the Al-Qassim region, the Buraydah, and its surroundings, as shown in Figure 3. Buraydah is the capital of the region and is located between 
longitudes $43^{\circ} 50^{\prime} 55.99^{\prime \prime}$ and $44^{\circ} 8^{\prime} 59.85^{\prime \prime} \mathrm{E}$ and latitudes $26^{\circ} 10^{\prime} 47.28^{\prime \prime} \mathrm{N}$ and $26^{\circ} 27^{\prime} 5.60^{\prime \prime} \mathrm{N}$. It has mainly dry weather [44]. The average annual rainfall in the area is about $125 \mathrm{~mm}[4,45]$.

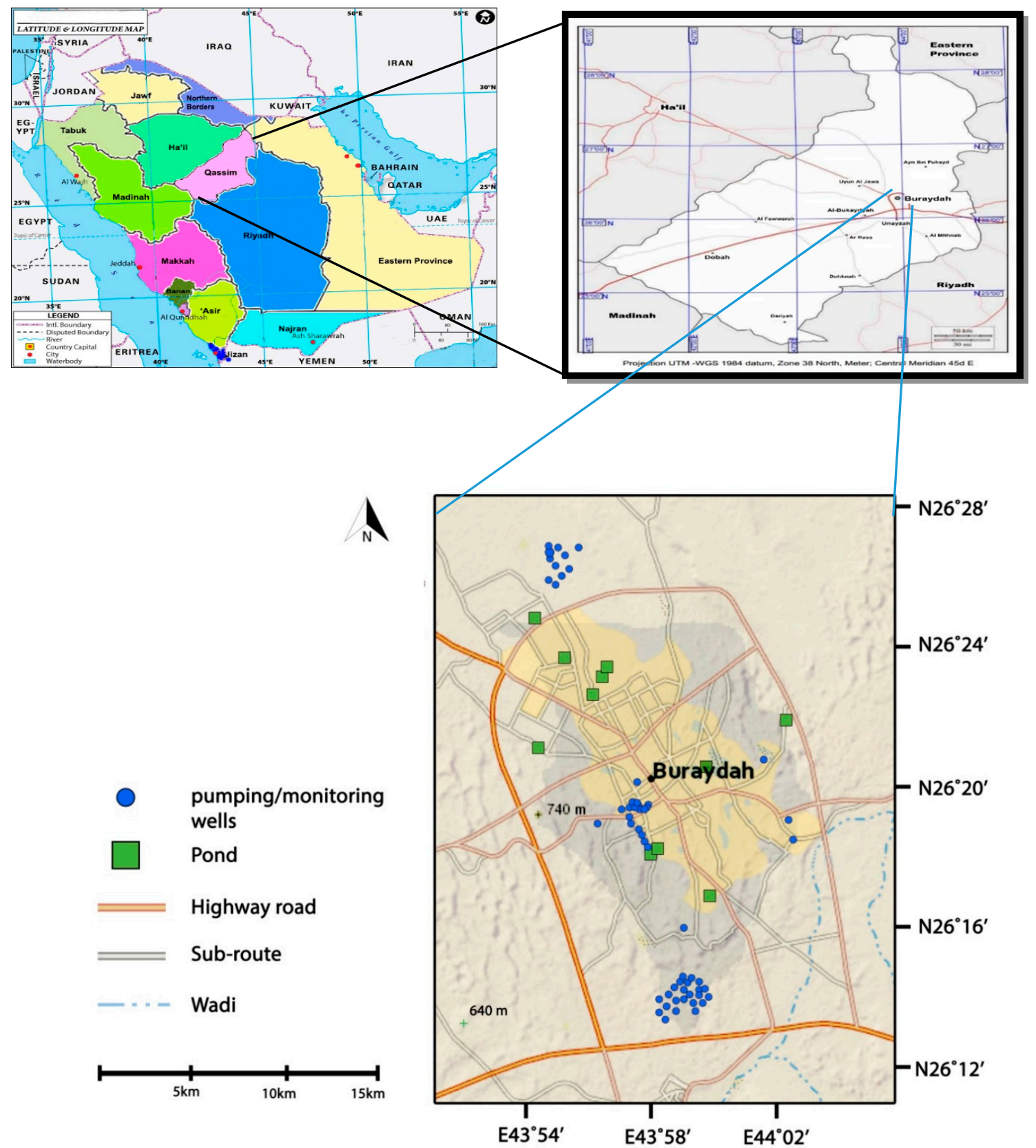

Figure 3. Map of the study area showing the locations of pumping wells (after Alotaibi et al. [44].

The water supply to the region is mainly dependent upon groundwater. The Saq Aquifer, which is one of the well-known aquifers in Saudi Arabia, is the major source of water supply. The cross-section of the Saq Aquifer is shown in Figure 4. The outcrop of the Saq aquifer is very vast. It encompasses nearly $1200 \mathrm{~km}$ only in Saudi Arabia, joining the Jordanian border as far south as longitude $45^{\circ} \mathrm{E}$ and latitude $24^{\circ} 30^{\prime} \mathrm{N}$. It is a confined aquifer with a variable thickness changing from $700 \mathrm{~m}$ in its northern part to $400 \mathrm{~m}$ in its southern part. The average thickness of the aquifer in the study area is nearly $500 \mathrm{~m}[4,45]$. 


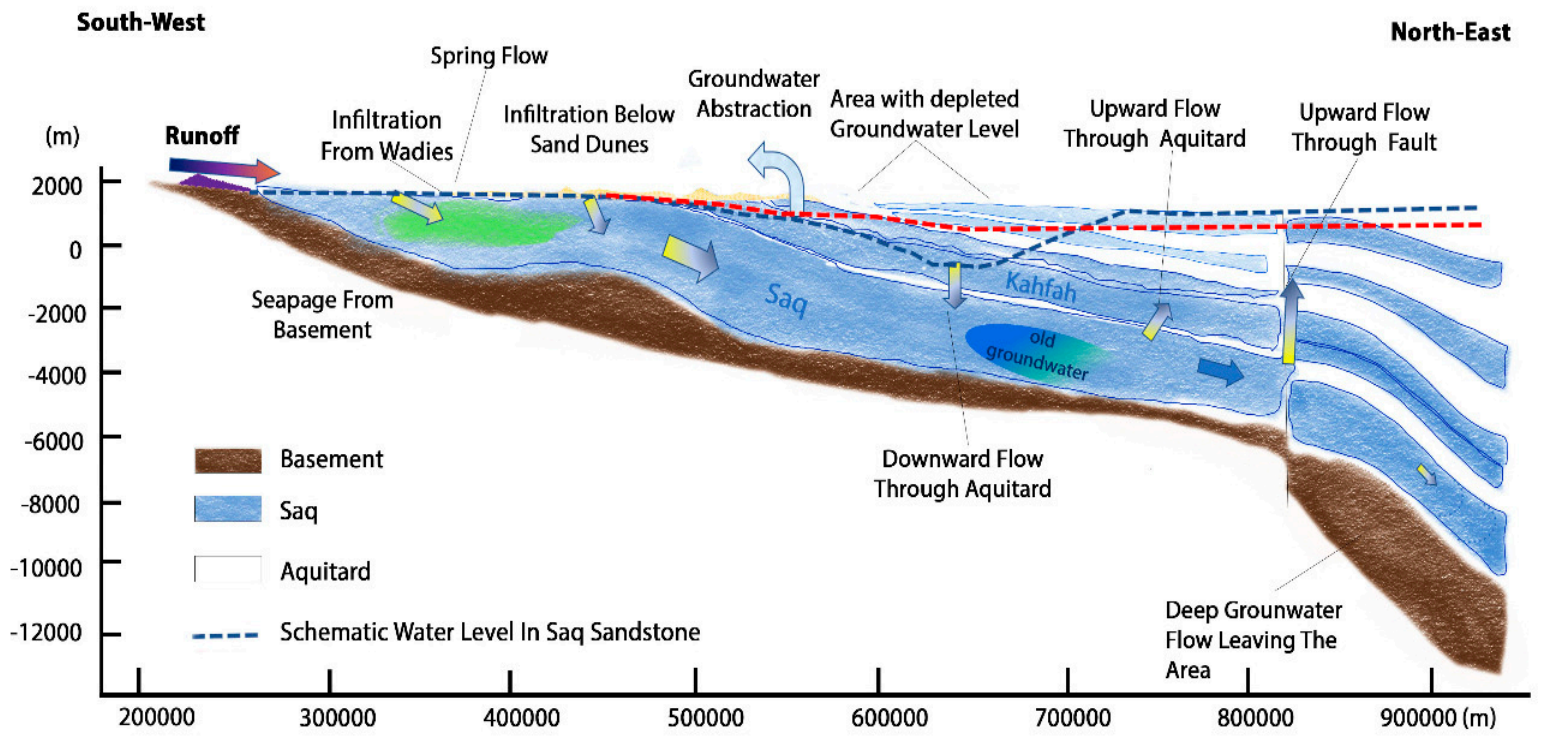

Figure 4. Cross-section of Saq Aquifer (After Al Salamah et al. [4]).

The subsurface strata comprise medium- to course-sized sandstone. There are some local areas containing fine sandstone also. The Saq aquifer groundwater has an electrical conductivity of approximately $0.276 \mathrm{~S} / \mathrm{m}$. The pumping wells are partially penetrating, having an average depth of about $650 \mathrm{~m}$. The screen of the wells is $125 \mathrm{~m}$ long [4].

\subsection{Description of Hydraulic Model (MODFLOW)}

The well-known Bossinesq equation governs groundwater flow is expressed as:

$$
\frac{\partial}{\partial x}\left(K_{x x} \frac{\partial h}{\partial x}\right)+\frac{\partial}{\partial y}\left(K_{y y} \frac{\partial h}{\partial y}\right)+\frac{\partial}{\partial z}\left(K_{z z} \frac{\partial h}{\partial z}\right)=S_{s} \frac{\partial h}{\partial t}-W
$$

where the values of the hydraulic conductivities are represented by $K x x, K y y$, and $K z z$ in the $x, y$, and $z$ directions, respectively, $h$ represents the groundwater-head, the specific storage of the aquifer is expressed by $S s, W$ represents a source/sink, and time is expressed by $t$. The finite difference scheme is applied to obtain the numerical solution to the above equation in the MODFLOW. The input and output data for MODFLOW is presented in Table 2. Selection of the mesh size and appropriate boundary conditions is highly challenging task in the case of the Saq aquifer. In this paper, a rectangular type mesh of $30 \times 20 \mathrm{~km}$ was developed by creating 80 rows and 70 columns. The number of rows and columns in the mesh were increased significantly to obtain denser mesh near the pumping wells for simulating the groundwater levels as precisely as possible. As mentioned earlier, the aquifer thickness (in the vertical direction) was $500 \mathrm{~m}$, above which there was an impermeable cover. The upper layer above the $500 \mathrm{~m}$ thick aquifer is about $628 \mathrm{~m}[4,45]$. The average ground surface level is around $600 \mathrm{~m}$ from the mean sea level. The pumping wells are partially penetrating wells with a screen length of $125 \mathrm{~m}$, so the confined part of the 500-m thick aquifer is divided into four layers, each of $125 \mathrm{~m}$, to simulate the screen effects precisely. In this way, five layers with thicknesses of $631,125,125,125$, and $125 \mathrm{~m}$ were considered, while the top layer was considered impermeable (Figure 5).

The parameters of the aquifer below the $600 \mathrm{~m}$ soil cover were found by the pumping test. The transmissivity of the aquifer was found to be $4500 \mathrm{~m}^{2} /$ day. The aquifer is confined, homogeneous, and isotropic. The hydraulic conductivity of the aquifer was found to be $3.6 \mathrm{~m} /$ day and was the same in all the three directions $(K x x=K y y=K z z)$. The recharge from the surface to the aquifer is negligible. The seepage from the basement and the deep groundwater outflow were considered negligible. The aquifer is very large and has known boundaries only at its ends and outcrops. There is 
continued pumping with negligible recharge, so the boundary conditions change continually. Hence, the choice of boundary conditions for the study area was a difficult task. The general head boundary condition was the appropriate choice and was adjusted by calibration. This is further explained in the calibration section.

Table 2. Input and output data for MODFLOW.

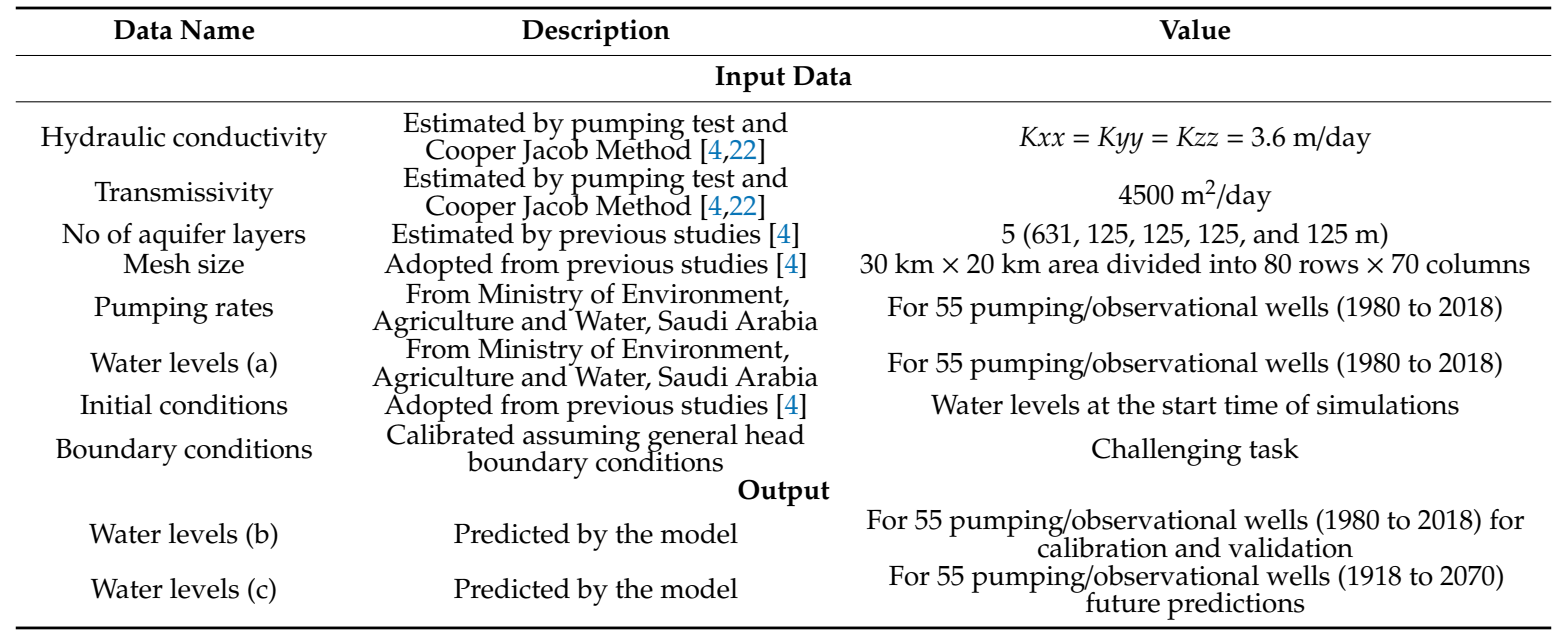

Monitoring Well

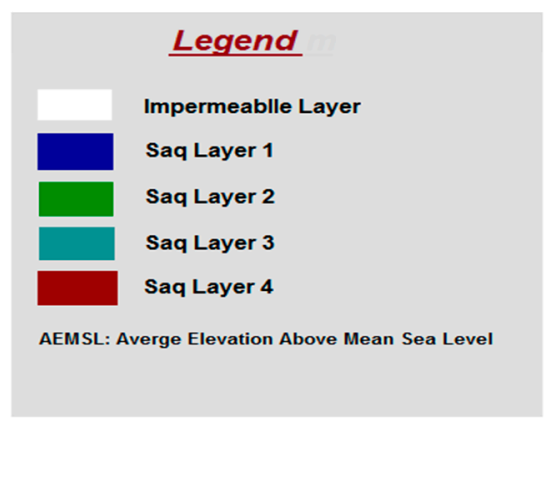

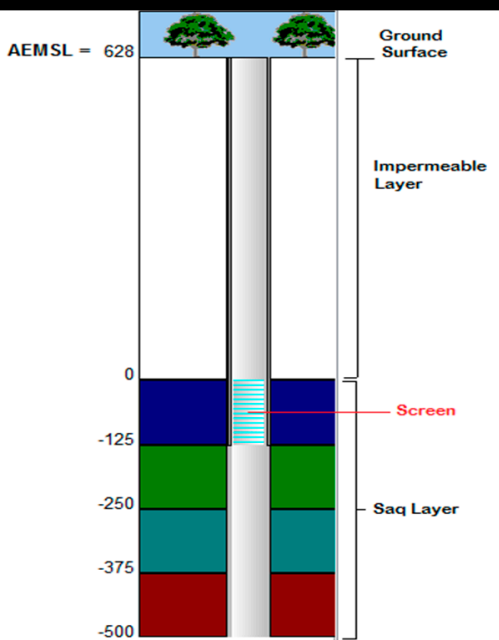

Figure 5. Layers of the Saq Aquifer for MODFLOW Models.

\subsection{Artificial Neural Networks (ANN)}

The artificial neural network (ANN) model is a data-driven model [41,46]. The ANN is one of the artificial intelligence techniques that simulates the actions of the human brain with the help of neurons. ANNs are becoming very common for hydrologic modeling and have been used to solve problems of applied nature in engineering and science $[47,48]$. These models may be congregated into two key categories: feed-forward and feed-back networks [46,47,49]. The most commonly used family of feed-forward networks contains a layered-network in which the neurons are organized in layers with unidirectional connections between the layers. This is known as multilayer perceptron (MLP) [47-49]. The input and output data for ANN are presented in Table 3. Figure 6a illustrates an MLP with three types of layers, including input, output, and hidden layer. The neurons in the input layer act as buffers for allocating the input signals to neurons in the hidden layer. The input signals can be expressed as $x_{i}(i=1,2, \ldots, n$ with $n$ being the total number of input signals). Each neuron $j$ in the hidden layer 
characterizes the sum of its input signals $x_{i}$ after weighting them with the strengths of the respective connections $w_{i j}$ from the input layer. It then calculates its output $y_{j}$ as a function $f$ of the sum of $w_{i j} \times x_{i}$.

Table 3. Input and output data/parameters for ANN.

\begin{tabular}{|c|c|c|}
\hline Parameter Name & Description & Value/Comment \\
\hline \multicolumn{3}{|c|}{ Input Data } \\
\hline Number of hidden layers & $\begin{array}{l}\text { Adopted to investigate the best } \\
\text { architecture of the model }\end{array}$ & Two to three \\
\hline Number hidden neurons in each layer & $\begin{array}{l}\text { Adopted to investigate the best } \\
\text { architecture of the model }\end{array}$ & 5 to $15(5,10,15)$ \\
\hline Activation functions & Tested various functions & - \\
\hline Pumping rates & $\begin{array}{l}\text { From Ministry of Environment, } \\
\text { Agriculture and Water, Saudi Arabia }\end{array}$ & $\begin{array}{l}\text { For selected pumping/observational } \\
\text { wells (1980 to 2018) }\end{array}$ \\
\hline Water levels (a) & $\begin{array}{l}\text { From Ministry of Environment, } \\
\text { Agriculture and Water, Saudi Arabia } \\
\text { Output }\end{array}$ & $\begin{array}{l}\text { For selected pumping/observational } \\
\text { wells (1980 to 2018) }\end{array}$ \\
\hline Water levels (b) & Predicted by the model & $\begin{array}{l}\text { For selected pumping/observational } \\
\text { wells (1980 to 2018) for } \\
\text { training/testing/validation }\end{array}$ \\
\hline
\end{tabular}

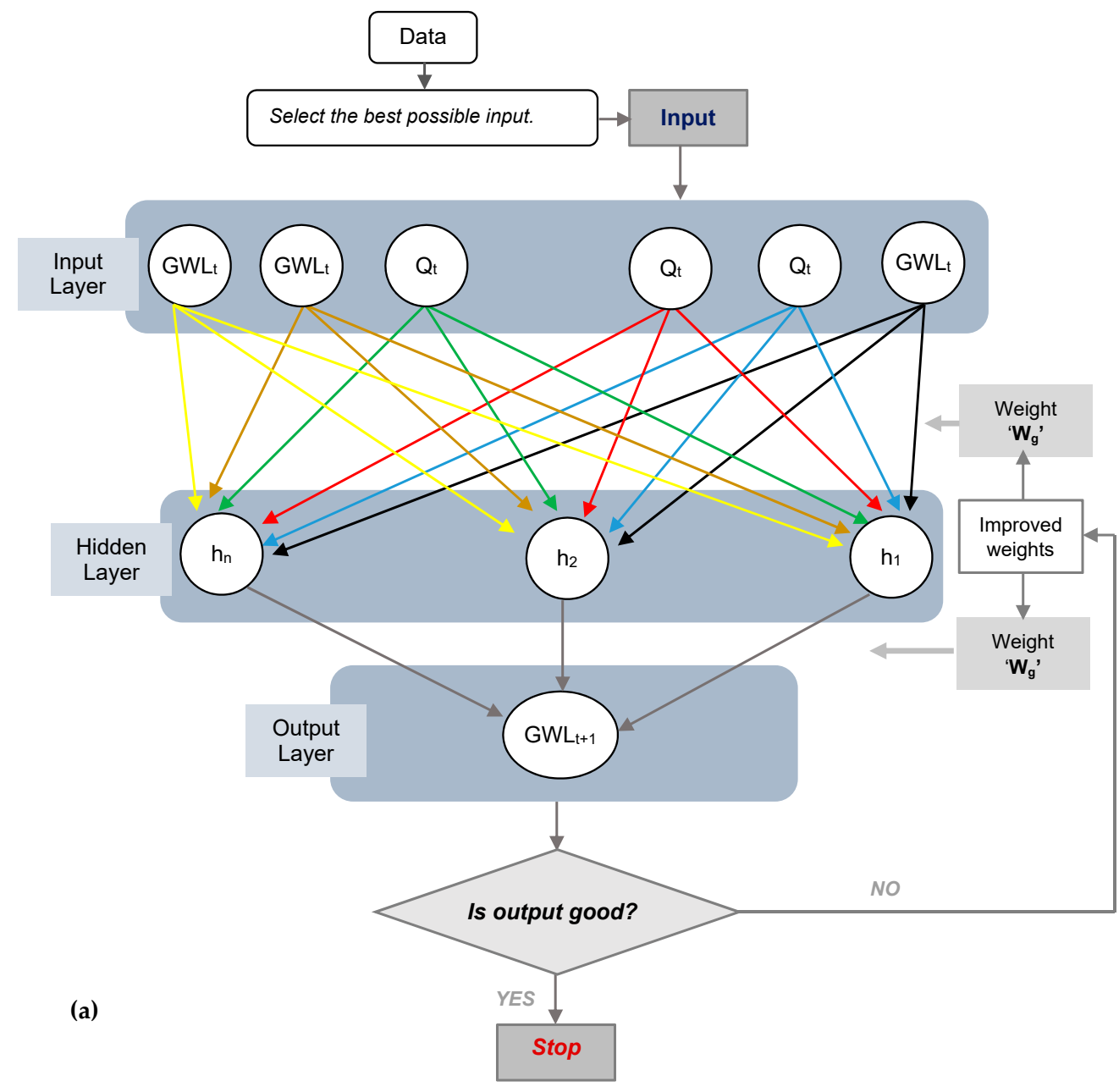

Figure 6. Cont. 


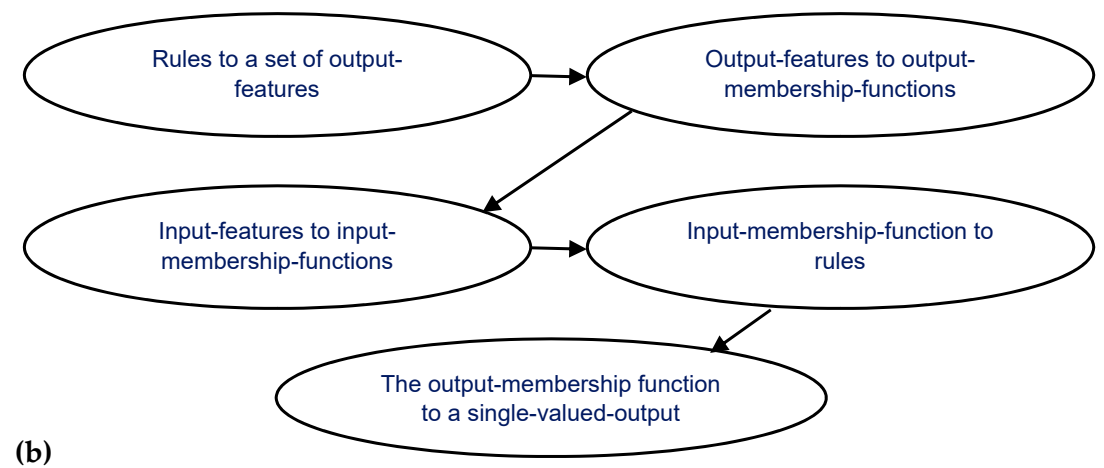

Figure 6. Modeling approach, (a) Flowchart representing the MLP (a feed-forward-ANN), (b) Five functional blocks in ANFIS.

Three of the built-in functions available in MATLAB (Levenberg Marquardt (LM), Bayesian regularization, and scaled conjugate gradient) were tested. The LM algorithm combines the merits of two training algorithms, namely the steepest descent and Gaussian-Newton methods, and searches for the global minima function to optimize the solution [41,47-49]. Bayesian regularization is a highly robust training algorithm for simulating the short-term fluctuations in groundwater levels. However, the Levenberg-Marquardt algorithm yields convergence comparatively more quickly than Bayesian regularization [49]. The scaled conjugate gradient is an efficient training algorithm with quick convergence and a high degree of accuracy [49-51].

The performance of the developed models was tested using Nash-Sutcliffe model efficiency (NSE) and mean square error (MSE), as explained in the coming sections. Finally, the results were generated for future groundwater levels using an ANN for Buraydah Qassim up to the year 2070 for various pumping rate scenarios.

\subsection{Adaptive Neuro Fuzzy Inference System}

ANFIS is a very popular branch of artificial intelligence models. A combination of fuzzy-if-then rules are used to describe the input-output relation of a real system in ANFIS [32,33]. The output of each of these rules is defined by a set of input variables and a constant term. The average of the weighted output of each rule becomes the concluding output. The functional block of ANFIS, consisting of fuzzification, inference, and defuzzification processes, is presented in Figure $6 \mathbf{b}[30,31]$.

\subsection{Model Performance Evaluation}

There are numerous statistical indices that are used for the evaluation of model performance. These indices are based on the comparison of measured and predicted data. It is worth noting that about 38 years (1980-2018) of data recorded for groundwater levels and pumping rates were used to check the performance of the models for various stages, including training/calibration, testing, and validation. A similar approach was adopted in previous studies $[44,52]$.

The parameters adopted in this study to measure the performance of the models are given by the following equations $[44,52,53]$. The Nash-Sutcliffe model efficiency (NSE) is given as:

$$
N S E=1-\frac{\sum_{i=1}^{n}\left(G W L_{i}^{o}-G W L_{i}^{p}\right)^{2}}{\sum_{i=1}^{n}\left(G W L_{i}^{o}-G W L_{a v g}\right)^{2}}
$$

where GWL is the variable representing the groundwater level, o is the observed value of GWL, $p$ represents the predicted value, and $\mathrm{n}$ denotes the total number of data points. As per the criteria adopted by Rauf and Ghumman [54], values from 0.75 to 1.0 of NSE can be categorized as 'very good', 0.65 to 0.75 can be considered 'good', 0.5 to 0.65 as 'satisfactory', and the values between 0.4 and 0.5 represent an 'acceptable' performance of the model. 
The mean bias error (MBE) is given as:

$$
M B E=\sum_{i=1}^{n} \frac{\left(G W L_{i}^{p}-G W L_{i}^{o}\right)}{n}
$$

The positive values of $M B E$ represent overestimated predictions whereas negative values are for underestimated predictions [54].

\section{Results and Discussion}

\subsection{Hydraulic Model Results}

The most important and challenging parameter in the calibration of the hydraulic model was the adjustment of the general head boundary condition. The results of calibration of MODFLOW are shown in Figure 7a,b. The NSE value was found to be 0.9. This value of NSE lies in the range of "very good" according to the criteria adopted by Rauf and Ghumman [54]. Furthermore, our results are similar to those of Mohanty et al. [55] and Lyons et al. [16], although the hydraulic conductivity and specific storage were the most sensitive parameters in the calibration phase of their groundwater hydraulic model, but adjustment of the boundary condition was most crucial issue in our case. The resultant predicted vs. observed line was close to the 45-degree line, which also showed that the results of calibration were "very good". The value of NSE for validation (0.87) was also in the "very good" range. Figure 8 b shows that some of the predicted groundwater depths were underestimated, whereas others were overestimated. A mean bias error (MBE) value of $0.89 \mathrm{~m}$ indicates that, as a whole, the groundwater levels are slightly overestimated. So, one has to be careful in the judgement of simulations. A very good NSE value does not guarantee perfect simulations. There should at least be one other check (Figure 8 b) to decide the fate of the model results.
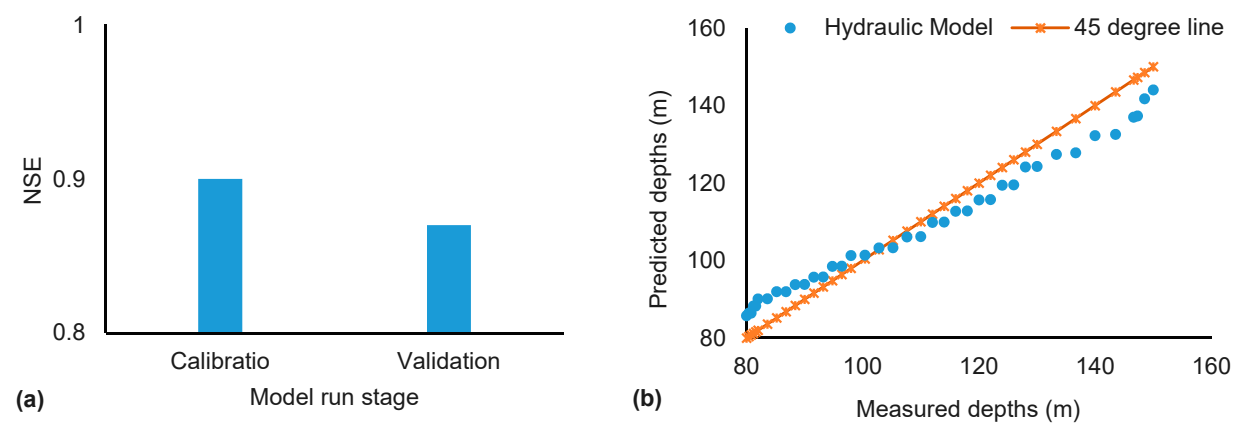

Figure 7. Results of MODFLOW (a) Performance parameter NSE, (b) Predicted vs observed water depths.
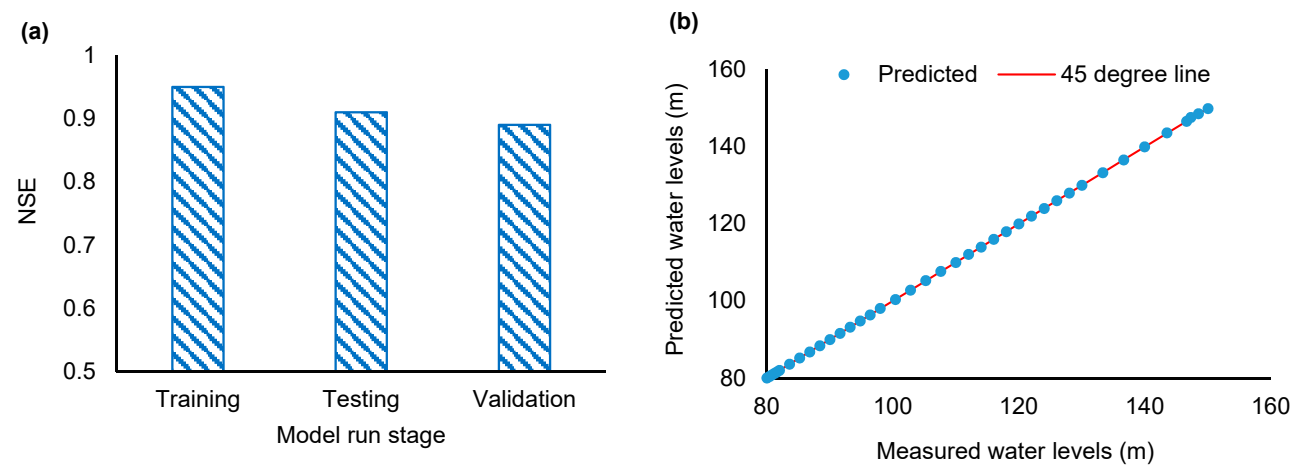

Figure 8. ANFIS Results for groundwater modeling; (a) Performance indicator, (b) Predicted verses observed groundwater levels. 


\subsection{ANFIS Results}

Figure $8 \mathrm{a}, \mathrm{b}$ presents the results of ANFIS. It is observed that ANFIS is highly efficient technique for simulation of groundwater levels. In Figure 8a,b, the NSE is 0.95 and the 45-degree line is very close to the predicted values of groundwater levels by ANFIS, which shows an excellent performance of ANFIS. Our results are in line with the past studies by Emamgholizadeh et al. [32] and Das [33].

\subsection{ANN Model Results}

In the case of ANN models, comparatively better performance was observed for ANNs with 10 hidden neurons in both the two-layer and three-layer architecture, as compared with those having 5 or 15 neurons (see Figure 9a,b). The value of NSE was comparatively higher when the models were run with 10 neurons. Figure 10a,b illustrates that the ANN performed better in the case with three layers, as compared with the two-layer architecture. For training, testing, and validation, NSE values were found to be $0.97,0.94$, and 0.92 , respectively, for the three-layer architecture and 0.96, 0.86, and 0.91 , respectively, for the two-layer architecture. The minimum value of NSE in these results was 0.86 , which also represents a "very good" performance (NSE range 0.75 to 1 represents "very good" performance [54].
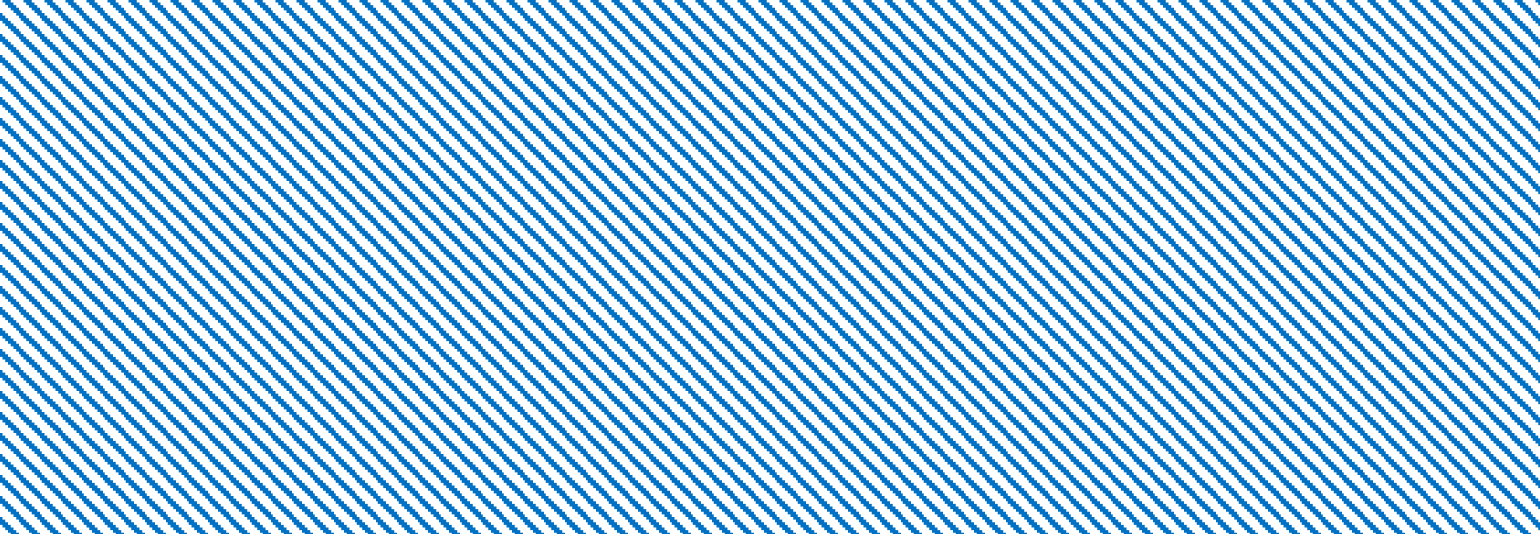

Figure 9. Comparison of the ANN results for 5, 10, and 15 hidden neurons in each layer: (a) two-layer architecture, (b) three-layer architecture.
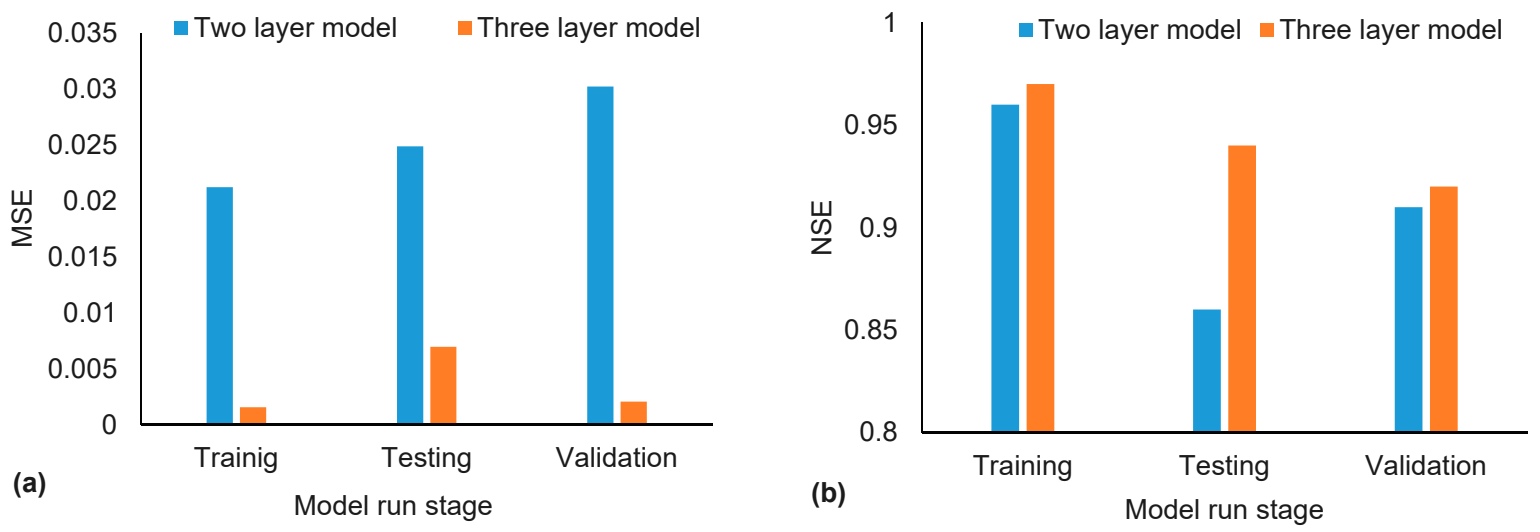

Figure 10. Comparison of ANN results for two- and three-layer architecture models with 10 neurons in each layer; (a) MSE values, (b) NSE values.

Further, the performance of the Scaled Conjugate Gradient training function was better than that of the Levenberg-Marquardt and Bayesian Regularization training functions for the three-layer 
architecture with 10 neurons (Figure 11a-d). Figure 11a shows that the predicted groundwater levels from scaled the conjugate gradient training function were comparatively closer to the 45-degree line (the 45-degree line shows the perfect matching between the predicted and measured groundwater-levels). However, as shown by Figure 11b, the results from the other two training functions, namely Levenberg-Marquardt and Bayesian Regularization, were also not bad. Figure 11c shows that the NSE values remained in the range of 0.65 to 0.97 . So, the overall performance of all the three models was "good" to "very good". This is further strengthened by Figure $11 \mathrm{~d}$ that shows a very low mean square error in the range of $0.02-0.03$. Similar results were observed by previous studies $[30,41,42,49]$. This is most probably because a stronger optimization scheme was used in the scaled conjugate gradient to get a better global minimum with the minimum possible number of trials $[16,54]$.
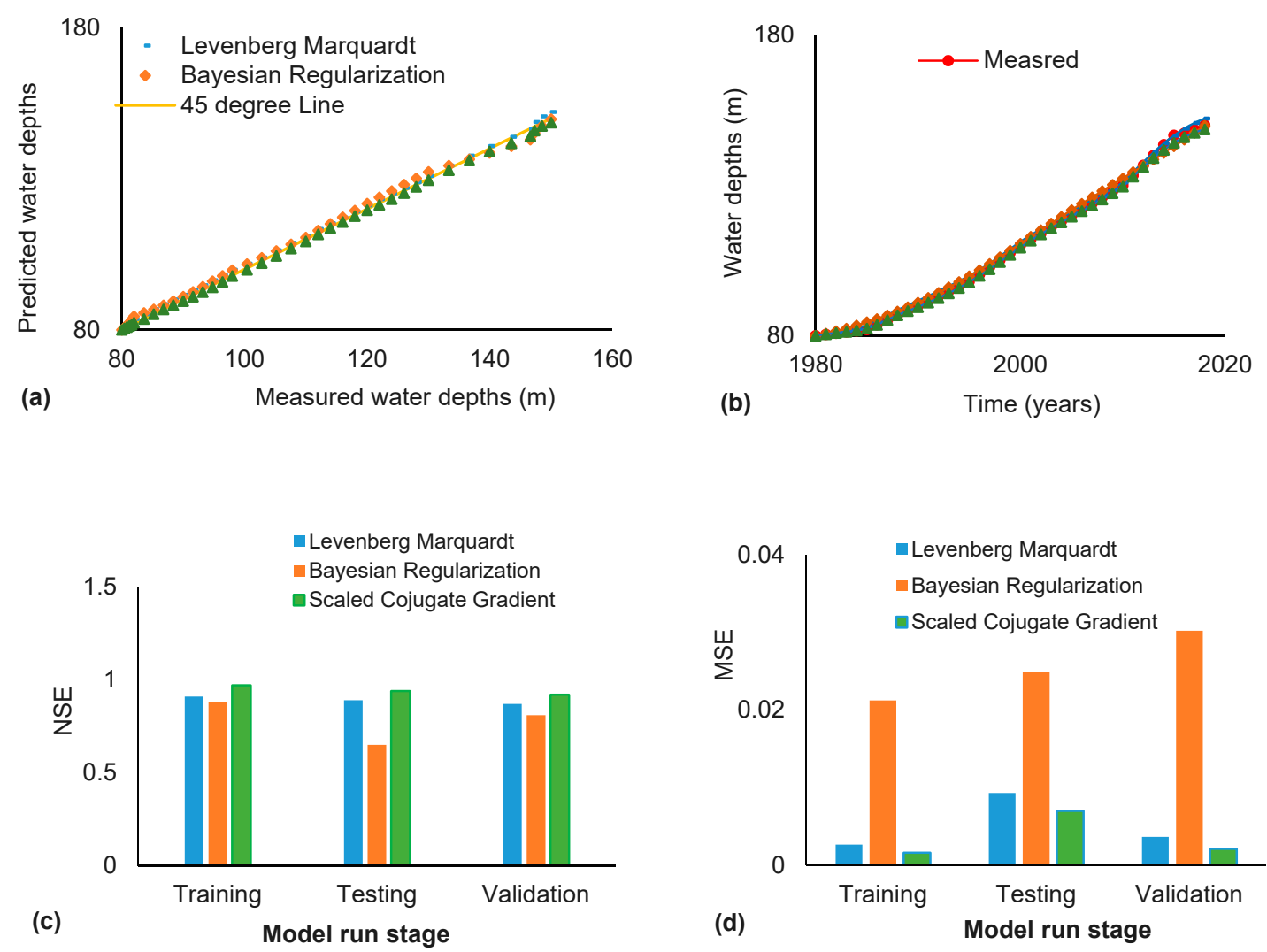

Figure 11. Comparison of the three ANN models. (a) Measured vs predicted groundwater levels, (b) Measured and predicted groundwater levels with respect to time showing depletion of aquifer,

(c) NSE values, (d) MSE values.

\subsection{Comparison of ANN, ANFIS and Hydraulic Model Results}

Figure 12 presents a comparison of results from various models with respect to their performance. It is observed that the performance of ANN and ANFIS models was better in the training stage as compared to that of the calibration of the MODFLOW. The mean-square-error was lower and the NSE was higher in the training stage of ANN and ANFIS models as compared with the mean-square-error and the NSE in the case of calibration of the MODFLOW. Our results support the results found by recent studies $[8,10,32,33,39,55]$. 

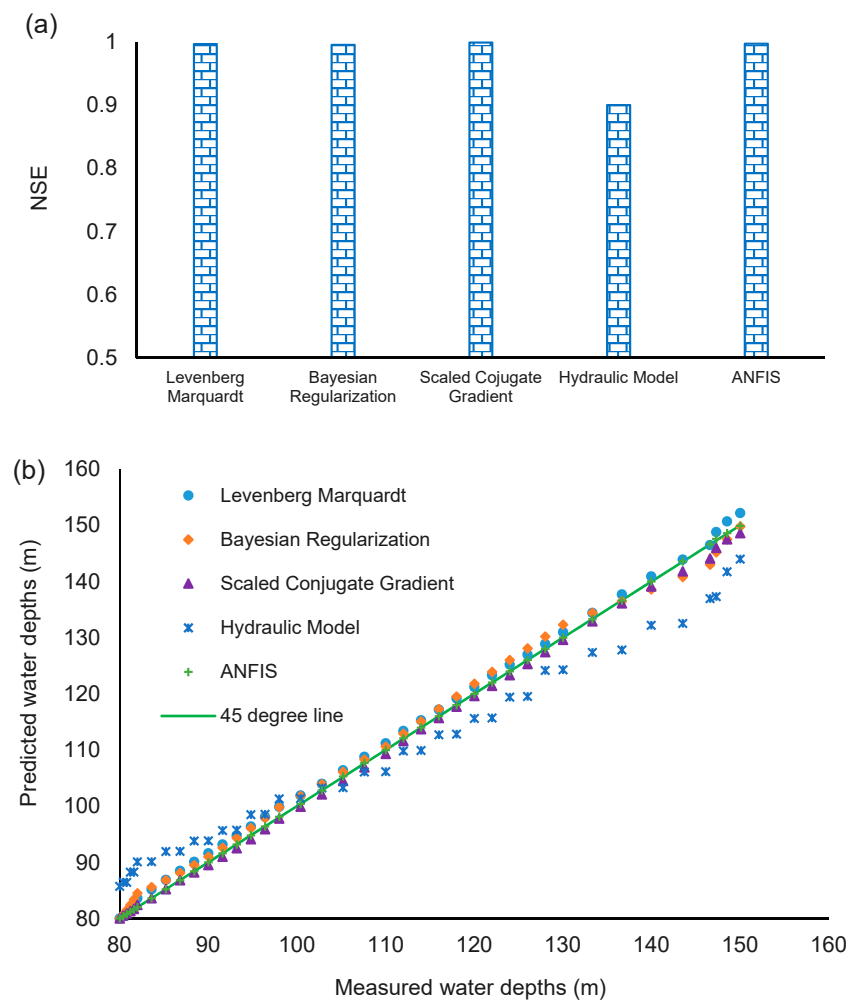

Figure 12. Comparison of the ANN and Hydraulic model. (a) NSE (b) Groundwater depths.

\subsection{Long-Term Predictions}

The predicted groundwater depths for various pumping rates scenarios are shown in Figure 13. The forecast of the drawdown up to the year 2070 with respect to the water level in 2018 was found to be $70-105 \mathrm{~m}(70,81.65,93.3$, and $105 \mathrm{~m})$ for four different options of pumping rates (keeping pumping rates constant or increasing by $1 \%, 2 \%$, and $3 \%$ per year as compared to the pumping rate in 2018 . The Saq Aquifer is covered by the Qassim Aquifer, which has contaminated shallow groundwater. Such a large drawdown in the Saq aquifer may result in a low pressure in the aquifer, allowing contaminated water from the overlying aquifer to enter into the aquifer. Hence, a serious environmental disaster may occur. So, it is very important to adopt some sustainable management strategies.

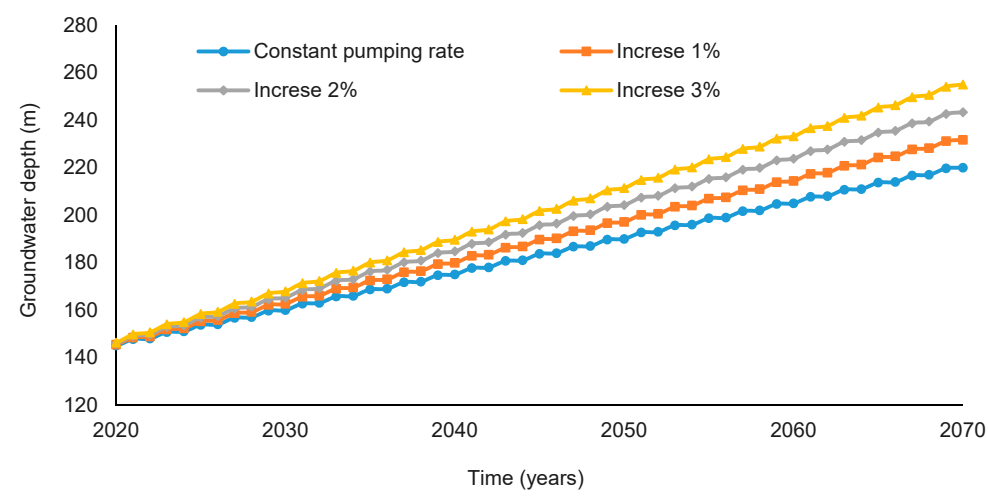

Figure 13. Future prediction results of groundwater depths/aquifer depletion for various pumping rate scenarios.

This research will be helpful in finding the sustainable pumping rates for future. For example, in case of constant pumping rate, there may be significant increase in the life of the Saq Aquifer. A $33 \%$ reduction in drawdown can be achieved in long-term (50 years in future) by adopting water 
conservation strategies in comparison to the continuously increasing pumping rates that are required to fulfil the water demands of rapidly increasing population. Results of study will facilitate in the planning and management of limited water resources in Saudi Arabia, the Gulf Region, and other arid regions with similar water stress conditions.

\section{Conclusions and Recommendations}

The hydraulic model MODFLOW predicted the changes in the groundwater levels of the Saq Aquifer in the vicinity of water supply pumping stations with 55 wells. ANN models effectively simulated the groundwater level changes around the same pumping stations. Two-layered and three-layered ANN models with 5, 10, and 15 hidden neurons in each layer were examined. Three types of training functions were investigated in ANN models. ANFIS has been applied successfully to simulate the aquifer depletion.

The study found that ANFIS can simulate groundwater levels efficiently with NSE up to 0.95. In the case of the ANNs, it provided the best performance with 10 hidden neurons in each layer. The ANNs with 10 hidden neurons in each layer perform better than those with five or 15 neurons. A three-layered architecture with 10 hidden neurons performs better than a two-layered architecture. Moreover, the scaled conjugate gradient performs better than the Levenberg-Marquardt and Bayesian regularization training functions. The hydraulic model is comparatively more reliable, but its performance for the given set of data is not as good as that of the ANN models.

Future predictions show that a substantial groundwater drawdown (ranging from 70 to $150 \mathrm{~m}$ ) in Saq Aquifer is expected in the next 50 years, with respect to the reference water levels in 2018. There may be a serious environmental disaster if precautionary measures are not taken. However, no increase in pumping rates may enhance the life of the Saq Aquifer significantly. The drawdown will reduce by 33\% compared with the drawdown in 2070 in the case of continued pumping at increasing rates to meet the water demands of the increasing population. There is hardly any recharge to the Saq Aquifer and it may vanish after some time. Therefore, new sources of water should be developed as per the goals of the country's Vision 2030.

Future research work on how new sources of water can be developed is recommended. Improvement in the presentation of the model is also suggested. More effective technology, sophisticated data, knowledge of outcrops, and appropriate management are needed for the study area. Meteorological, hydraulic, hydrologic, and detailed geological data for the whole of the Qassim Region should be collected for wide-ranging hydraulic and ANN modeling. A comparison of various conventional and deep learning artificial intelligence methods is also recommended.

Author Contributions: Conceptualization, M.R.A., A.R.G. and I.S.A.-S.; methodology, M.R.A., A.R.G. and Y.M.G., software, M.R.A., A.A. and Y.M.G.; validation, A.A. and Y.M.G.; formal analysis, M.R.A.; investigation, A.R.G. and H.H.; resources, I.S.A.-S.; data curation, M.R.A. and A.A.; writing-original draft preparation, M.R.A., A.R.G. and H.H.; writing-review and editing, H.H. and M.S.; visualization, M.R.A. and A.R.G.; supervision, A.R.G. and Y.M.G.; project administration, I.S.A.-S. All authors have read and agreed to the published version of the manuscript.

Funding: This research received no external funding.

Acknowledgments: Authors acknowledge the Ministry of Environment, Water, and Agriculture in Saudi Arabia for data sharing. The authors are thankful to the Administration of the College of Engineering (Dean and Vice Dean Administration) and the Head of the Civil Engineering Department for their continued support in this research.

Conflicts of Interest: The authors declare no conflict of interest.

\section{References}

1. Wendt, D.E.; Loon, A.F.V.; Bloomfield, J.P.; Hannah, D.M. Asymmetric impact of groundwater use on groundwater droughts. Hydrol. Earth Syst. Sci. 2020. [CrossRef]

2. Afzaal, H.; Farooque, A.A.; Abbas, F.; Acharya, B.; Esau, T. Groundwater Estimation from Major Physical Hydrology Components Using Artificial Neural Networks and Deep Learning. Water 2020, 12, 5. [CrossRef] 
3. Vergnes, J.; Roux, N.; Habets, F.; Ackerer, P.; Amraoui, N.; Besson, F.; Caballero, Y.; Courtois, Q.; Dreuzy, J.; Etchevers, P.; et al. The AquiFR hydrometeorological modelling platform as a tool for improving groundwater resource monitoring over France: Evaluation over a 60-year period. Hydrol. Earth Syst. Sci. 2020, 24, 633-654. [CrossRef]

4. Al Salamah, I.S.; Ghazaw, Y.; Ghumman, A.R. Groundwater modeling of Saq Aquifer Buraydah Al Qassim for better water management strategies. Environ. Monit. Assess 2011, 173, 851-860. [CrossRef]

5. Devarajan, K.; Sindhu, G. Application of Numerical and Empirical Models for Groundwater Level Forecasting. Int. J. Res. Eng. Technol. 2015, 4, 11, 127-133.

6. Hariharan, V.; Shankar, M.U. A review of visual MODFLOW applications in groundwater modelling. IOP Conf. Ser. Mater. Sci. Eng. 2017, 263, 032025. [CrossRef]

7. Arlai, P.; Koch, M.; Lukjan, A. Numerical investigation of sustainable groundwater yields for the Wiang Pa Pao aquifer system in northern Thailand, Songklanakarin. J. Sci. Technol. 2018, 40, 577-587.

8. Bizhanimanzar, M.; Leconte, R.; Nuth, M. Modelling of shallow water table dynamics using conceptual and physically based integrated surface-water-groundwater hydrologic models. Hydrol. Earth Syst. Sci. 2019, 23, 2245-2260. [CrossRef]

9. Filippis, G.D.; Pouliaris, C.; Kahuda, D.; Vasile, T.A.; Manea, V.A.; Zaun, F.; Panteleit, B.; Dadaser-Celik, F.; Positano, P.; Nannucci, M.S.; et al. Spatial Data Management and Numerical Modelling: Demonstrating the Application of the QGIS-Integrated FREEWAT Platform at 13 Case Studies for Tackling Groundwater Resource Management. Water 2020, 12, 41. [CrossRef]

10. Bizhanimanzar, M.; Leconte, R.; Nuth, M. Catchment-Scale Integrated Surface Water-Groundwater Hydrologic Modelling Using Conceptual and Physically Based Models: A Model Comparison Study. Water 2020, 12, 363. [CrossRef]

11. McDonald, M.G.; Harbaugh, A.W. A modular three-dimensional finite-difference ground-water flow model. In Techniques of Water-Resources Investigations, Book 6; U.S. Geological Survey: Reston, VA, USA, 1988.

12. Jin-sheng, J.; Liu, C. Groundwater dynamic drift and response to different exploitation in the North China Plain: A case study of Luancheng County, Hebei Province. ACTA Geogr. Sin. Chin. Ed. 2002, 57, 201-209.

13. Joseph, Z.; Tarhule, A. Simulating the impacts of groundwater pumping on stream-aquifer dynamics in semiarid northwestern Oklahoma, USA. Hydrogeol. J. 2008, 16, 797-810.

14. Vijay, R.; Mohapatra, P.K. Hydrodynamic assessment of coastal aquifer against saltwater intrusion for city water supply of Puri, India. Environ. Earth Sci. 2016, 75, 1-8. [CrossRef]

15. Sundararajan, N.; Sankaran, S. Groundwater modeling of Musi basin Hyderabad, India: A case study. Appl. Water Sci. 2020, 10, 14. [CrossRef]

16. Lyons, R.T.; Peralta, R.C.; Majumder, P. Comparing Single-Objective Optimization Protocols for Calibrating the Birds Nest Aquifer Model-A Problem Having Multiple Local Optima. Int. J. Environ. Res. Public Health 2020, 17, 853. [CrossRef] [PubMed]

17. Kavvas, M.L.; Tu, T.; Ercan, A.; Polsinelli, J. Fractional governing equations of transient groundwater flow in unconfined aquifers with multi-fractional dimensions in fractional time. Earth Syst. Dyn. 2020, 11, 1-12. [CrossRef]

18. Pujades, E.; Carrera, J.; Vázquez-Suñé, E.; Jurado, A.; Vilarrasa, V.; Mascuñano-Salvador, E. Hydraulic characterization of diaphragm walls for cut and cover tunneling. Eng. Geol. 2012, 125, 1-10. [CrossRef]

19. Pujades, E.; Jurado, A.; Carrera, J.; Vázquez-Suñé, E.; Dassargues, A. Hydrogeological assessment of non-linear underground enclosures. Eng. Geol. 2016, 207, 91-102. [CrossRef]

20. Theis, C.V. The relation between the lowering of the piezometric surface and the rate and duration of discharge of a well using groundwater storage. Am. Geophys. Union Trans. 1935, 16, 519-524. [CrossRef]

21. Pujades, E.; De Simone, S.; Carrera, J.; Vázquez-Suñé, E.; Jurado, A. Settlements around pumping wells: Analysis of influential factors and a simple calculation procedure. J. Hydrol. 2017, 548, 225-236. [CrossRef]

22. Cooper, H.H., Jr.; Jacob, C.E. A generalized graphical method for evaluating formation constants and summarizing well-field history. Eos Trans. Am. Geophys. Union 1946, 27, 526-534. [CrossRef]

23. Aghlmand, R.; Abbasi, A. Application of MODFLOW with Boundary Conditions Analyses Based on Limited Available Observations: A Case Study of Birjand Plain in East Iran. Water 2019, 11, 1904. [CrossRef]

24. Wu, H.N.; Shen, S.L.; Chen, R.P.; Zhou, A. Three-dimensional numerical modelling on localized leakage in segmental lining of shield tunnels. Comput. Geotech. 2020, 122, 103549. [CrossRef] 
25. Zeng, C.F.; Xue, X.L.; Zheng, G.; Xue, T.Y.; Mei, G.X. Responses of retaining wall and surrounding ground to pre-excavation dewatering in an alternated multi-aquifer-aquitard system. J. Hydrol. 2018, 559, 609-626. [CrossRef]

26. Zeng, C.F.; Zheng, G.; Xue, X.L. Responses of deep soil layers to combined recharge in a leaky aquifer. Eng. Geol. 2019, 260, 105263. [CrossRef]

27. Elbaz, K.; Shen, S.L.; Zhou, A.; Yuan, D.J.; Xu, Y.S. Optimization of EPB shield performance with adaptive neuro-fuzzy inference system and genetic algorithm. Appl. Sci. 2019, 9, 780. [CrossRef]

28. Elbaz, K.; Shen, S.L.; Sun, W.J.; Yin, Z.Y.; Zhou, A. Prediction model of shield performance during tunneling via incorporating improved Particle Swarm Optimization into ANFIS. IEEE Access 2020, 8, 39659-39671. [CrossRef]

29. Gao, M.U.; Zhang, N.; Shen, S.L.; Zhou, A. Real-time dynamic regulation of earth pressure for shield tunneling using GRU deep learning method. IEEE Access 2020, 8, 64310-64323. [CrossRef]

30. Jeong, J.; Park, E. Comparative applications of data-driven models representing water table fluctuations. J. Hydrol. 2019, 572, 261-273. [CrossRef]

31. Seifi, A.; Ehteram, M.; Singh, V.P.; Mosavi, A. 2020, Modeling and Uncertainty Analysis of Groundwater Level Using Six Evolutionary Optimization Algorithms Hybridized with ANFIS, SVM, and ANN. Sustainability 2020, 12, 4023. [CrossRef]

32. Emamgholizadeh, S.; Moslemi, K.; Karami, G. Prediction the Groundwater Level of Bastam Plain (Iran) by Artificial Neural Network (ANN) and Adaptive Neuro-Fuzzy Inference System (ANFIS). Water Resour. Manag. 2014, 28, 5433-5446. [CrossRef]

33. Das, U.K.; Roy, P.; Ghose, D.K. Modeling water table depth using adaptive Neuro-Fuzzy Inference System. ISH J. Hydraul. Eng. 2019, 25, 291-297. [CrossRef]

34. Yoon, H.; Jun, S.; Hyun, Y.; Bae, G.; Lee, K. A comparative study of artificial neural networks and support vector machines for predicting groundwater levels in a coastal aquifer. J. Hydrol. 2011, 396, 128-138. [CrossRef]

35. Chitsazan, M.; Rahmani, G.; Neyamadpour, A. Forecasting Groundwater Level by Artificial Neural Networksas an Alternative Approach to Groundwater Modeling. J. Geol. Soc. India 2015, 85, 98-106. [CrossRef]

36. Supreetha, B.S.; Shenoy, N.; Nayak, P. Lion Algorithm-Optimized Long Short-Term MemoryNetwork for Groundwater Level Forecasting in Udupi District, India. Appl. Comput. Intellig. Soft Comput. 2020, 8685724. [CrossRef]

37. Panahi, P.; Sadhasivam, N.; PourghasemI, H.R.; Rezaie, F.; Lee, S. Spatial prediction of groundwater potential mapping based on convolutional neural network $(\mathrm{CNN})$ and support vector regression (SVR). J. Hydrol. 2020, 572, 435-448.

38. Fan, Y.; Hu, L.; Wang, H.; Liu, X. Machine Learning Methods for Improved Understanding of a Pumping Test in Heterogeneous Aquifers. Water 2020, 12, 1342. [CrossRef]

39. Chen, C.; He, W.; Zhou, H.; Xue, Y.; Zhu, M. A comparative study among machine learning and numerical models for simulating groundwater dynamics in the Heihe River Basin, northwestern China. Sci. Rep. 2020, 10, 3904. [CrossRef]

40. Ji, K.; Chen, X.; Aldahan, A.; Yi, P.; Murad, A.; Hussein, S.; Alshamsi, D.; Ahmed, M.M.; Yu, Z. Chronology and characteristics of groundwater along the United Arab Emirates-Oman arid region: A guide for regional sustainability. J. Radioanal. Nucl. Chem. 2020, 323, 1055-1070. [CrossRef]

41. Djurovic, N.; Domazet, M.; Stricevic, R.; Pocuca, V.; Spalevic, V.; Pivic, R.; Gregoric, E.; Domazet, U. Comparison of Groundwater Level Models Based on Artificial Neural Networks and ANFIS, Hindawi Publishing Corporation. Sci. World J. 2015, 2015. [CrossRef]

42. Khedri, A.; Kalantari, N.; Vadiati, M. Comparison study of artificial intelligence method for short term groundwater level prediction in the northeast Gachsaran unconfined aquifer. Water Supply 2020, 20, 909-921. [CrossRef]

43. Gonand, F. Impacts of Higher Energy Efficiency on Growth and Welfare Across Generations in Saudi Arabia; KS-1657-DP051A; King Abdul Aziz Petroleum Studies and Research Centre: Riyadh, Saudi Arabia, 2016.

44. Alotaibi, K.; Ghumman, A.R.; Haider, H.; Ghazaw, Y.; Shafiquzzaman, M. Future Predictions of Rainfall and Temperature Using GCM and ANN for Arid Regions: A Case Study for the Qassim Region, Saudi Arabia. Water 2018, 10, 1260. [CrossRef] 
45. Al Salamah, I.S. To Develop a Useful Management Tool for Water Resources Allocation in the Saq Aquifer in Al-Qassim Region, Saudi Arabia. Ph.D. Thesis, Iowa State University, Ames, IA, USA, 2000.

46. Alsumaiei, A.A. A Nonlinear Autoregressive Modeling Approach for Forecasting Groundwater Level Fluctuation in Urban Aquifers. Water 2020, 12, 820. [CrossRef]

47. Samarasinghe, S. Neural Networks for Applied Sciences and Engineering: From Fundamentals to Complex Pattern Recognition; Auerbach Publications: New York, NY, USA, 2016; ISBN 0429115784.

48. Wunsch, A.; Liesch, T.; Broda, S. Forecasting groundwater levels using nonlinear autoregressive networks with exogenous input (NARX). J. Hydrol. 2018, 567, 743-758. [CrossRef]

49. Taormina, R.; Chau, K.-W.; Sethi, R. Artificial neural network simulation of hourly groundwater levels in a coastal aquifer system of the Venice lagoon. Eng. Appl. Artifi. Intellig. 2012, 25, 1670-1676. [CrossRef]

50. Lohani, A.K.; Krishan, G. Groundwater Level Simulation Using Artificial Neural Network in Southeast, Punjab, India. J. Geolo. Geophy. 2015, 4, 206. [CrossRef]

51. Farizawani, A.G.; Puteh, M.; Marina, Y.; Rivaie, A. A review of artificial neural network learning rule based on multiple variant of conjugate gradient approaches. J. Phys. Conf. Ser. 2020, 1529, 022040. [CrossRef]

52. Ghumman, A.R.; Rauf, A.; Haider, H.; Shafiquzamman, M. Functional data analysis of models for predicting temperature and precipitation under climate change scenarios. J. Water Clim. Chang. 2019. [CrossRef]

53. Abulohom, M.S.; Shah, S.M.S.; Ghumman, A.R. Development of a rainfall-runoff model, its calibration and validation. J. Water Resour. Manag. 2002, 15, 149-163. [CrossRef]

54. Rauf, A.; Ghumman, A.R. Impact Assessment of Rainfall-Runoff Simulations on the Flow Duration Curve of the Upper Indus River-A Comparison of Data-Driven and Hydrologic Models. Water 2018, 10, 876. [CrossRef]

55. Mohanty, S.; Madan, K.J.; Kumar, A.; Panda, D.K. Comparative evaluation of numerical model and artificial neural network for simulating groundwater flow in Kathajodi-Surua Inter-basin of Odisha, India. J. Hydrol. 2013, 495, 38-51. [CrossRef]

(C) 2020 by the authors. Licensee MDPI, Basel, Switzerland. This article is an open access article distributed under the terms and conditions of the Creative Commons Attribution (CC BY) license (http://creativecommons.org/licenses/by/4.0/). 